\title{
Contractility and supersensitivity to adrenaline in dystrophic muscle
}

\author{
M. TAKAMORI \\ From the First Department of Internal Medicine, Nagasaki University School of Medicine, \\ Nagasaki, Japan
}

SYNOPSIS In the adductor pollicis muscle of patients with limb-girdle and facioscapulohumeral muscular dystrophies and possible carriers of Duchenne type muscular dystrophy, abnormal active state properties were found at the time when there was no alteration of needle electromyography and evoked muscle action potentials. Adrenaline induced a marked reduction of incomplete tetanus via beta receptors without change in neuromuscular transmission.

In Duchenne type muscular dystrophy, Desmedt et al. (1968) demonstrated disordered contractility in the adductor pollicis muscle at a preclinical stage, antedating any recordable change in the electrical activity; they thus suggested abnormalities in the intrinsic muscular elements as early changes of the disease. On the basis of Hill's concept of the active state (Buller, 1969), the present investigation was attempted to confirm their postulate in adult dystrophic patients and also in carriers of Duchenne dystrophy. An attempt was also made to estimate a chemosensitive property of contraction in dystrophic muscle using adrenaline. Marsden and Meadows (1970) first demonstrated effects of adrenaline on skeletal muscle of the normal human subject and suggested its direct action on the mechanism of contraction. We made the same measurement as theirs in the adductor pollicis muscle of normal and dystrophic patients. We suggest that the present pharmacophysiological study is useful in evaluating subcellular changes of dystrophic muscle at the time when muscle electrical activity and clinical state are normal, and also in the detection of carriers. The recent hypothesis that muscular dystrophy is of neurogenic origin is discussed in connexion with the results of the present investigation.

\section{METHODS}

The clinical investigation was carried out with 20 (Accepted 14 January 1975.) normal subjects ( 10 men aged 20 to 41 years and 10 women aged 21 to 48 years); 23 patients with limbgirdle muscular dystrophy (14 men aged 18 to 41 years and nine women aged 20 to 39 years), six patients with facioscapulohumeral dystrophy (five men aged 20 to 49 years and a woman aged 21 years); and six possible carriers (women aged 30 to 42 years) of Duchenne type muscular dystrophy. The diagnosis of limb-girdle and facioscapulohumeral dystrophies was made on the basis of the history, physical examination, muscle biopsy, serum creatine phosphokinase (CPK), and concentric needle electromyography. Electromyographic study of 29 dystrophic patients showed decreased mean duration of motor unit potentials and increased proportion of polyphasic motor unit potentials in proximal muscles but not in distal muscles, including the adductor pollicis, which was investigated in the present study. There was no increased muscle irritability on movement of the needle electrode in the adductor pollicis of any patient. Six mothers of boys with Duchenne type dystrophy were defined as 'possible carriers' on the basis of family history and pedigree. Two mothers showed elevated values of serum CPK (30 and 111 Ebashi units; the upper limit of normal, 20 Ebashi units), but four mothers were normal in terms of enzyme study and electromyography. Nerve conduction velocity and neuromuscular transmission (as evaluated by muscle responses to nerve stimulation at rates of 1 to $50 \mathrm{~Hz}$ and post-tetanic muscle responses to single stimuli (Takamori, 1972; Takamori et al., 1972) were normal in all 35 patients.

Simultaneous electrical and mechanical responses (Fig. 1) were elicited from the adductor pollicis with supramaximal electrical stimulation $(0.5 \mathrm{~ms}$ dura483 
tion) of the ulnar nerve at the wrist through an electronic stimulator (Nihon Kohden, MSE-40), isolation transformer (Nihon Kohden, MSE-JH) and bipolar $5 \mathrm{~mm}$-diameter surface stimulating electrodes $2 \mathrm{~cm}$ apart. The adductor pollicis muscle action potential (electrical response) was recorded by $5 \mathrm{~mm}$-diameter silver disc electrodes placed over the end-plate zone and the dorsal surface of the first metacarpal bone, and was measured on the first channel of an oscilloscope (Nihon Kohden, VC-7A) with a plug-in amplifier (Nihon Kohden, AVB-2). The indifferent electrode was placed at a distance of $4 \mathrm{~cm}$ from the stigmatic electrode. The distance between the stimulating cathode and the stigmatic recording electrode was set at $8.8 \pm 0.2 \mathrm{~cm}$. Thumb adduction (mechanical response) was recorded isometrically through a strain gauge and carrier amplifier (Nihon Kohden, RM-5), and was measured on the second channel of the oscilloscope. The first channel for action potential swept 10 times as fast as the second channel. Using the equipment described by Slomic et al. (1968), the forearm, hand, and all fingers except the thumb were immobilized rigidly in a metal frame without interference with the blood circulation; the middle of the first phalanx of the thumb was attached vertically to an isometric strain gauge and flexion of the thumb due to ulnar nerve stimulation was prevented by a horizontal bar attached to the holder. Accurate linearity of relationship between the voltage output of the strain gauge myograph system and the load was confirmed up to $15 \mathrm{~kg}$ loading. The resonant frequency exceeded 400 $\mathrm{Hz}$. The strain gauge myograph was also transferred to differentiators; the first and second differentials were recorded on an ink-writing oscilloscope (Nihon Kohden, W1-130M). The muscle was maintained at $35^{\circ} \mathrm{C}$ monitored by a needle thermocouple thrust into the first dorsal interosseous muscle for about $1 \mathrm{~cm}$ towards the adductor pollicis. The resting tension was set in order to obtain maximal twitch force. Twitch distortion due to the back response (Merton, 1954; Brown and Matthews, 1960) was excluded by paired nerve stimulation at interstimulus intervals of 0.2 to $0.9 \mathrm{~ms}$. This was also checked during the periods of post-tetanic and staircase twitch potentiations and of adrenaline infusion.

Isometric contraction was analysed in terms of the concept of the active state, which is subdivided into the time component (active state duration and decay) and the intensity component (active state intensities of shortening and load-bearing). The maximum twitch force $\left(\mathbf{P}_{t}\right)$ and half-relaxation time $\left(T_{1 / 2 R}\right)$ (from the onset of twitch development to the point of half-maximum tension through to the peak of twitch tension) were measured (Fig. 1). The time from the onset of the negative deflection of the action
TABLE

CONTRACTILE PROPERTIES OF MUSCLE

\begin{tabular}{|c|c|}
\hline Abbreviations & Functions \\
\hline $\mathbf{P}_{\mathrm{t}}$ (maximum twitch force) & $\begin{array}{l}\text { Force generated by contractile } \\
\text { component plus series-elastic } \\
\text { component }\end{array}$ \\
\hline $\begin{array}{l}T_{1 / 2 R} \text { (half-relaxation time) } \\
T_{\mathrm{dPt} / \mathrm{dt}} \text { (time to maximum velocity) } \\
\mathrm{d}^{2} \mathrm{Pt} / \mathrm{dt}^{2} \text { (maximum acceleration) }\end{array}$ & $\begin{array}{l}\text { Decay of active state } \\
\text { Duration of active state } \\
\text { Active state intensity of } \\
\text { shortening }\end{array}$ \\
\hline $\mathbf{P}_{\mathrm{o}}$ (maximum tetanic force) & $\begin{array}{l}\text { Active state intensity of load- } \\
\text { bearing }\end{array}$ \\
\hline $\begin{array}{l}\mathrm{d}_{\mathrm{Po} / \mathrm{dt}} \text { (maximum velocity of } \\
\text { tetanus development }\end{array}$ & Force-velocity relation \\
\hline
\end{tabular}

potential to the peak of the first differential (maximum velocity, $d_{P t / d t}$ ) is represented by $T_{d P t / a t}$. The peak of the second differential $\left(\mathrm{d}^{2}{ }_{\mathrm{Pt} / \mathrm{dt}}{ }^{2}\right)$ represents the maximum acceleration of twitch development (Fig. 1). The maximum tetanic force $\left(\mathrm{P}_{\mathrm{o}}\right)$ and maximum velocity of tetanus development $\left(\mathrm{d}_{\mathrm{Po} / \mathrm{at}}\right)$ were studied using $250 \mathrm{~Hz}$ repetitive nerve stimulation (Fig. 1), which was postulated as an optimal frequency to obtain $\mathrm{P}_{\mathrm{o}}$ and $\mathrm{d}_{\mathrm{Po} / \mathrm{d}}$ (Desmedt et al., 1968a). The active state properties expressed by these measurements are summarized in the Table.

To study post-tetanic changes of muscle twitcho the conditioning tetanus was induced by repetitive $\overrightarrow{0}$ nerve stimulation at the rate of $50 \mathrm{~Hz}$ for 15 seconds जे the test twitch was elicited three minutes after the conditioning tetanus and was expressed as percent of a control twitch elicited before the conditioning tetanus. To study staircase changes of muscle twitch, repetitive nerve stimulations were given for two minutes at the rate of $1 \mathrm{~Hz}$ and the 120th response was expressed in terms of the percentage of the first response. In both studies, data were considered reliable only when the simultaneously recorded action potentials showed no significant change in amplitude or duration.

In the pharmacological study, the following drugs were administered by continuous infusion, using a motorized syringe: $10 \mu \mathrm{g} / \mathrm{min}$ adrenaline hydrochloride, $200 \mu \mathrm{g} / \mathrm{min}$ phenylephrine hydrochloride, $10 \mu \mathrm{g} / \mathrm{min}$ isoprenaline hydrochloride, and $1 \mathrm{mg} / \mathrm{min}$ propranolol hydrochloride. Five milligrams of phentolamine mesylate in a physiological saline $\frac{7}{2}$ solution $(0.5 \mathrm{ml})$ were administered intravenously for five minutes. Electrophysiological studies were $N$ begun five minutes after starting the continuous infusion of drugs or immediately after the phentolamine injection had been completed. Effects of drugs on muscle contractile properties were estimated by measuring the single twitch, staircase twitch change 

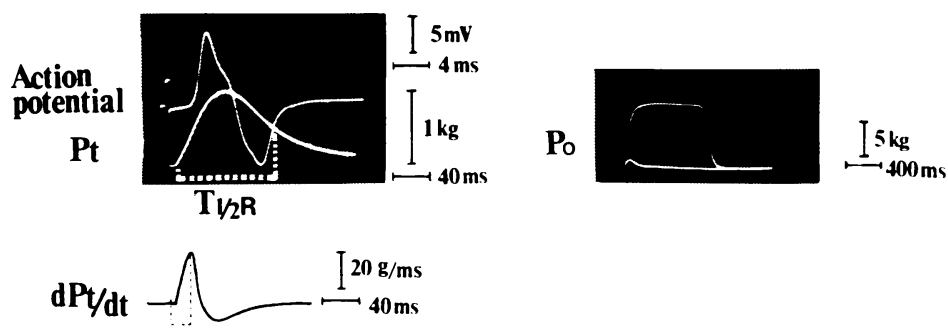

$\mathrm{TdPt} / \mathrm{dt}$

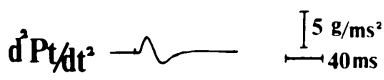

FIG. 1 Action potential and simultaneously recorded isometric twitch $\left(\mathrm{P}_{\mathrm{t}}\right)$ with first $\left(\mathrm{d}_{\mathrm{P} / \mathrm{d} \mathrm{t}}\right)$ and second $\left(\mathrm{d}^{2} \mathrm{Pt} / \mathrm{dt}{ }^{2}\right)$ differentials on the left, and maximum tetanus $\left(\mathrm{P}_{\mathrm{o}}\right)$ elicited by $250 \mathrm{~Hz}$ repetitive stimulation and its first differential $\left(\mathrm{d}_{\mathrm{Po} / \mathrm{dt}}\right)$ on the right (27 year old normal man).
$(1 \mathrm{~Hz})$, incomplete tetanus $(10 \mathrm{~Hz})$, and maximum tetanus $(250 \mathrm{~Hz})$. In the case of incomplete tetanus, the median tension calculated as the midpoint between the peak and the trough of oscillation at the 10th response was used as an index. Simultaneously recorded action potentials were measured as an index of neuromuscular transmission. Only one drug or a combination of two drugs (sympathomimetic amine and adrenergic blocker) was administered on any single day. During the infusion of adrenaline, changes in blood pressure and heart rate were monitored; electrophysiological data were considered reliable only when the range of the former change was from $+10 \%$ to $+25 \%$ and the latter from $+15 \%$ to $+40 \%$. Muscle temperature was maintained at $35^{\circ} \mathrm{C}$.

\section{RESULTS}

ISOMETRIC TWITCH RESPONSE TO A SINGLE STIMULATION (Figs 1 and 2) In 20 normal subjects, $P_{t}$ ranged from 811 to $1250 \mathrm{~g}$, and $\mathrm{T}_{1 / 2 \mathrm{R}}$ from 100 to $133 \mathrm{~ms}$. $\mathrm{T}_{\mathrm{dPt} / \mathrm{dt}}$ ranged from 17.4 to $25.8 \mathrm{~ms}$, and $\mathrm{d}^{2}{ }_{\mathrm{Pt} / \mathrm{dt}^{2}}$ from 1.8 to $3.2 \mathrm{~g} /$ $\mathrm{ms}^{2}$. Of the action potentials recorded simultaneously with the twitches, the amplitude, duration, and latency time (negative deflection) were 4.5 to $10.3 \mathrm{mV}, 3.8$ to $5.4 \mathrm{~ms}$, and 2.2 to $3.1 \mathrm{~ms}$, respectively. Of 35 patients ( 23 with limb-girdle dystrophy, six with facioscapulohumeral dystrophy, and six possible carriers of Duchenne dystrophy), the $P_{t}$ was below the normal range in 18 patients (335 to $800 \mathrm{~g} ; 13$ limb-girdle dystrophy, three facioscapulohumeral dystrophy, and two possible carriers of Duchenne dystrophy); $\mathrm{T}_{1 / 2 \mathrm{R}}$ was longer than the normal range in 15 patients (138 to $170 \mathrm{~ms} ; 12$ limb-girdle dystrophy and three facioscapulohumeral dys- trophy, but none of Duchenne carriers); $T_{d P t / d t}$ was longer than the normal range in 17 patients (26.4 to $38.4 \mathrm{~ms}$; 13 limb-girdle dystrophy, three facioscapulohumeral dystrophy, and one carrier of Duchenne type dystrophy); and $\mathrm{d}^{2}{ }_{\mathrm{Pt} / \mathrm{dt}}{ }^{2}$ was below the normal range in 23 patients $(0.6$ to 1.7
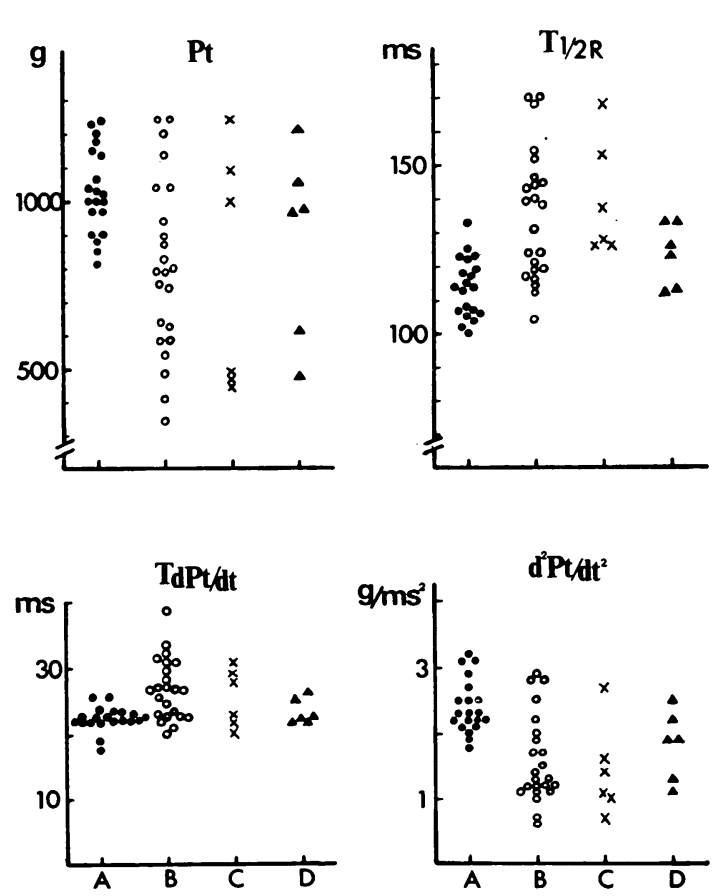

FIG. 2 Factors of single isometric twitch in 20 normal subjects (A, ), 23 patients with.limb-girdle dystrophy (B, $\bigcirc)$, six patients with facioscapulohumeral dystrophy $(\mathrm{C}, \times)$, and six possible carriers of Duchenne type dystrophy (D, $\Delta)$. 


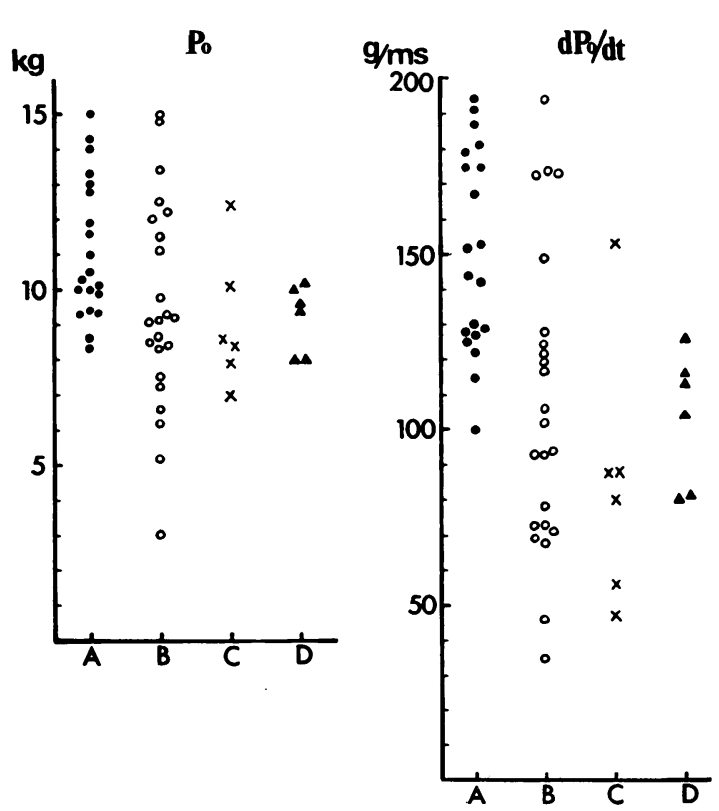

FIG. 3 Factors of maximum tetanus in 20 normal subjects $(\mathrm{A}, \mathrm{O}), 23$ limb-girdle dystrophy $(\mathrm{B}, \mathrm{O})$, six facioscapulohumeral dystrophy $(\mathrm{C}, \times)$, and six carriers of Duchenne dystrophy $(\mathrm{D}, \mathbf{\Delta})$.

$\mathrm{g} / \mathrm{ms}^{2}$; 16 limb-girdle dystrophy, five facioscapulohumeral dystrophy, and two carriers of Duchenne dystrophy). Amplitude, duration, and latency time of the simultaneously recorded action potentials (negative deflection) were within the normal ranges.

TETANUS ELICITED BY $250 \mathrm{HZ}$ REPETITIVE STIMULATION (Figs 1 and 3) In 20 normal subjects, the $P_{o}$ ranged from 8.3 to $15 \mathrm{~kg}$, and the $\mathrm{d}_{\mathrm{Po} / \mathrm{dt}}$ ranged from 100 to $194.4 \mathrm{~g} / \mathrm{ms}$. Of 35 patients, the $P_{o}$ was below the normal range in 10 patients ( 3 to $8 \mathrm{~kg}$; six limb-girdle dystrophy, two facioscapulohumeral dystrophy, and two Duchenne dystrophy carriers), and the $\mathrm{d}_{\mathrm{Po} / \mathrm{dt}}$ was below the normal range in 18 patients $(34.7$ to $94.5 \mathrm{~g} / \mathrm{ms}$; 11 limb-girdle dystrophy, five facioscapulohumeral dystrophy, and two Duchenne dystrophy carriers).

POST-TETANIC CHANGES OF ISOMETRIC TWITCH (Fig. 4) In 20 normal subjects, the $P_{t}$ and $\mathrm{d}^{2}{ }_{\mathrm{Pt} / \mathrm{dt}}{ }^{2}$ were markedly increased (119 to $165 \%$,
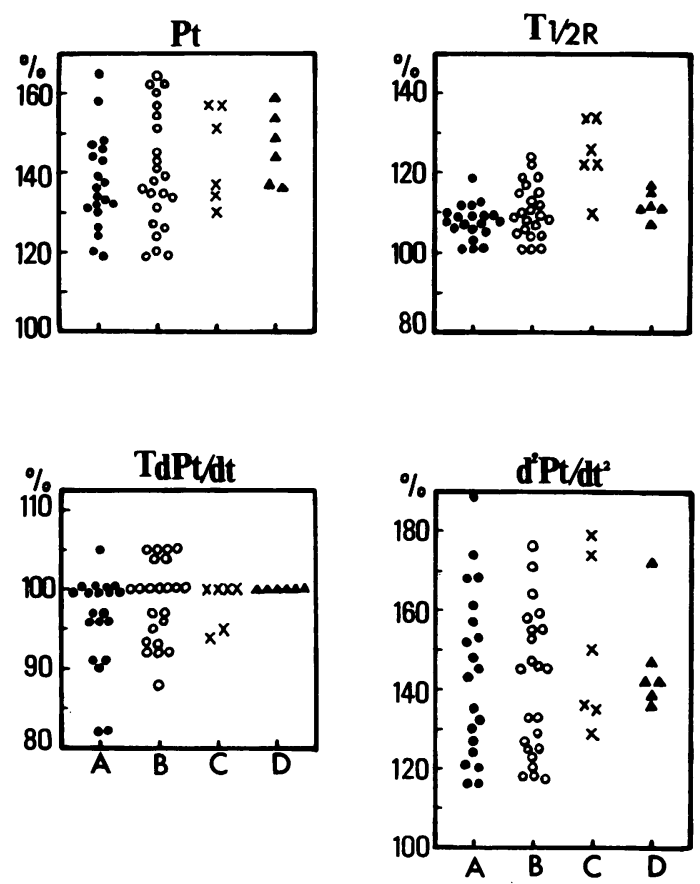

FIG. 4 Effects of conditioning tetanus on contractive factors of single test twitch elicited three minutes afteg tetanus in 20 normal subjects (A, O), 23 limb-gird延 dystrophy $(\mathrm{B}, \bigcirc)$, six facioscapulohumeral dystroph $(\mathrm{C}, \times)$, and six carriers of Duchenne dystroph of (D, $\Delta)$.

and 116 to $189 \%$ of the unconditioned twitch, respectively) three minutes after the conditioning $\overrightarrow{\overrightarrow{0}}$ tetanus. The $T_{1 / 2 R}$ was prolonged up to $119 \%$ of the unconditioned twitch; changes of the $\mathrm{T}_{\mathrm{dPt} / \mathrm{at}}$ ranged from 84 to $110 \%$ of the unconditioned twitch. Of 35 patients, post-tetanic changes in muscle contraction were within normal range except that the $T_{1 / 2 \mathrm{R}}$ showed abnormal posttetanic prolongation (122 to $134 \%$ ) in seven patients (two limb-girdle dystrophy and five facioscapulohumeral dystrophy, but none of Duchenne dystrophy carriers).

STAIRCASE CHANGES OF ISOMETRIC TWITCH (Fig. 5) In 20 normal subjects, the staircase $P_{t}$ potentiation reached 105 to $139 \%$ of the first response at the 120 th response during repetitive stimulations at the rate of $1 \mathrm{~Hz}$. Commensurate with $\mathrm{P}_{\mathrm{t}}$ potentiation, $\mathrm{d}^{2}{ }_{\mathrm{Pt} / \mathrm{dt}}{ }^{2}$ increased reaching 

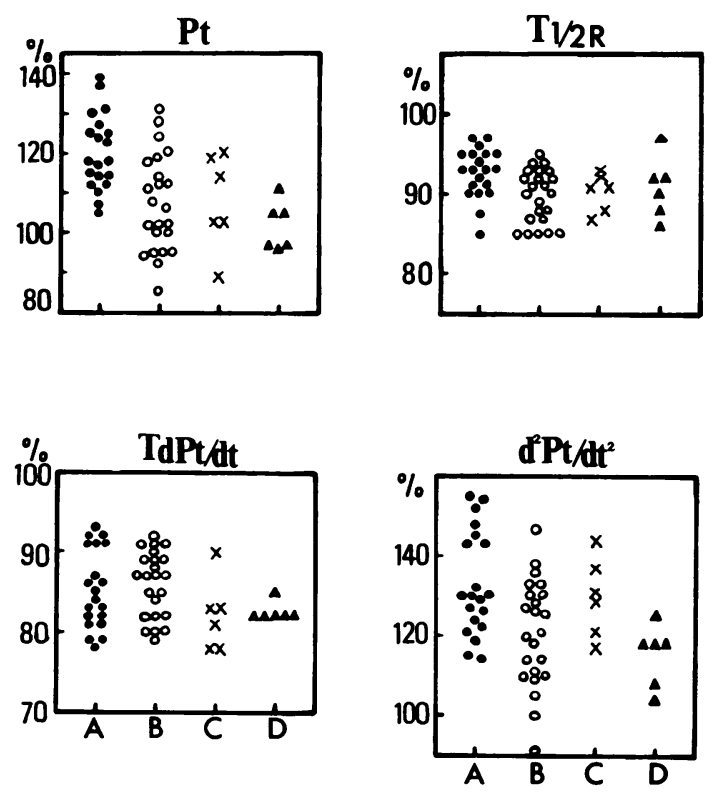

FIG. 5 Effects of $1 \mathrm{~Hz}$ repetitive stimulation on contractile factors of 120th test twitch in 20 normal subjects $(\mathrm{A}, \mathrm{O}), 23$ limb-girdle dystrophy $(\mathrm{B}, \mathrm{O})$, six facioscapulohumeral dystrophy $(\mathrm{C}, \times)$, and six carriers of Duchenne dystrophy $(\mathrm{D}, \mathrm{\Delta})$.

114 to $155 \%$ of the first response at the 120 th response, while $\mathrm{T}_{1 / 2 \mathrm{R}}$ and $\mathrm{T}_{\mathrm{dPt} / \mathrm{dt}}$ decreased (85 to $97 \%$ and 78 to $93 \%$ of the first response, respectively, at the 120 th response). Of 35 patients, less than normal $P_{t}$ potentiation or negative staircase phenomenon ( 85 to $103 \%$ ) was seen in 17 patients (11 limb-girdle dystrophy, three facioscapulohumeral dystrophy, and three carriers of Duchenne dystrophy); nine of these did not reach the normal range of change in $\mathrm{d}^{2}{ }_{\mathrm{Pt} / \mathrm{dt}^{2}}$ (91 to $110 \%$ ).

EFFECTS OF SYMPATHOMIMETIC AMINES IN MUSCLE CONTRACTION (Figs 6, 7, and 8) In 10 normal subjects, 19 patients with limb-girdle dystrophy, two patients with facioscapulohumeral dystrophy, and six possible carriers of Duchenne dystrophy, adrenaline was given intravenously at a rate of $10 \mu \mathrm{g} / \mathrm{min}$. The adrenaline effect was estimated by measuring changes of the median tension at the 10th response during the incomplete tetanus evoked by $10 \mathrm{~Hz}$ repetitive stimulation and was expressed as percentage of the preadrenaline level. This proved to be 75 to $91 \%$ in 10 normal subjects; 19 of the 27 patients showed a reduction below this normal range (33 to $67 \%$; 13 limb-girdle dystrophy, two facioscapulohumeral dystrophy, and four Duchenne dystrophy carriers) (Fig. 6). Muscle action potentials were evoked by $10 \mathrm{~Hz}$ repetitive stimulation of the nerve during the stage of reduction in the incomplete tetanus, and showed no significant change (Fig. 7). When the single twitch and staircase phenomenon $(1 \mathrm{~Hz})$ were used as indices for the adrenaline effect, the former decreased with a

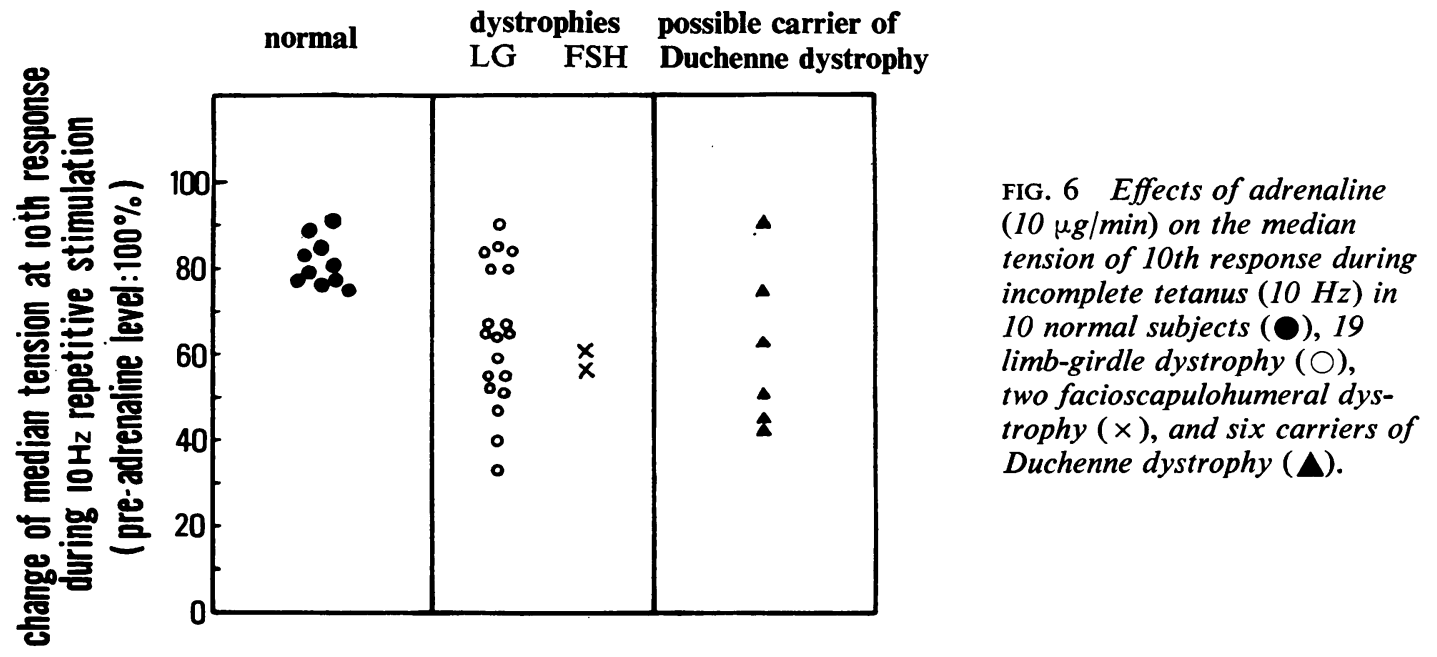

FIG. 6 Effects of adrenaline (10 $\mu \mathrm{g} / \mathrm{min})$ on the median ension of 10th response during complete tetanus $(10 \mathrm{~Hz})$ in limb-girdle dystrophy ( $\bigcirc)$, two facioscapulohumeral dystrophy $(\times)$, and six carriers of Duchenne dystrophy ( $\Delta)$. 


\section{Effect of adrenaline}

before during infusion $(10 \mu \mathrm{g} / \mathrm{min})$

incomplete tetanus $(10 \mathrm{~Hz})$
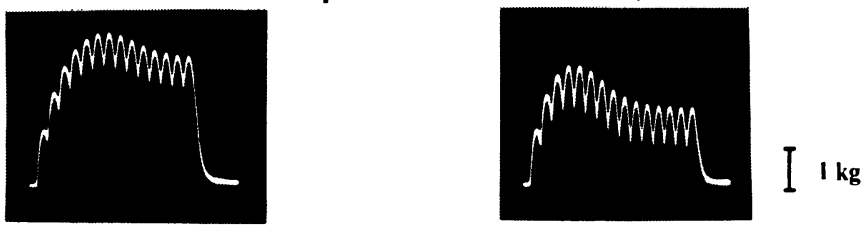

muscle responses evoked with nerve stimulation $(10 \mathrm{~Hz})$
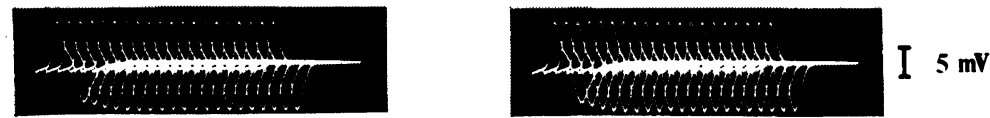

FIG. 7 Effects of adrenaline

(10 $\mu \mathrm{g} / \mathrm{min})$ on incomplete tetanus $(10 \mathrm{~Hz})$ (top), and muscle action potentials evoked by $10 \mathrm{~Hz}$ repetitive stimulation of the nerve (bottom) in a 29 year old man with limb-girdle dystrophy.

shortening of the $T_{1 / 2 R}$ in only two of 10 normals and six of 27 dystrophics, and the latter became less potentiated in association with less than normal increase or decrease of the $\mathrm{d}^{2}{ }_{\mathrm{Pt} / \mathrm{dt}^{2}}$ in three normals and seven dystrophics. Changes in both indices during the infusion of adrenaline did not differ significantly between normal and dystrophic groups. Adrenaline produced no change in the maximum tetanus $\left(\mathrm{P}_{\mathrm{o}}\right.$ by $250 \mathrm{~Hz}$ stimulation) in either group.

When adrenaline caused a reduction $(51 \%$ of the pre-adrenaline level), propranolol (betablocker) caused a decrease of the adrenaline effect $(84 \%)$, while phentolamine (alpha-blocker $\$$

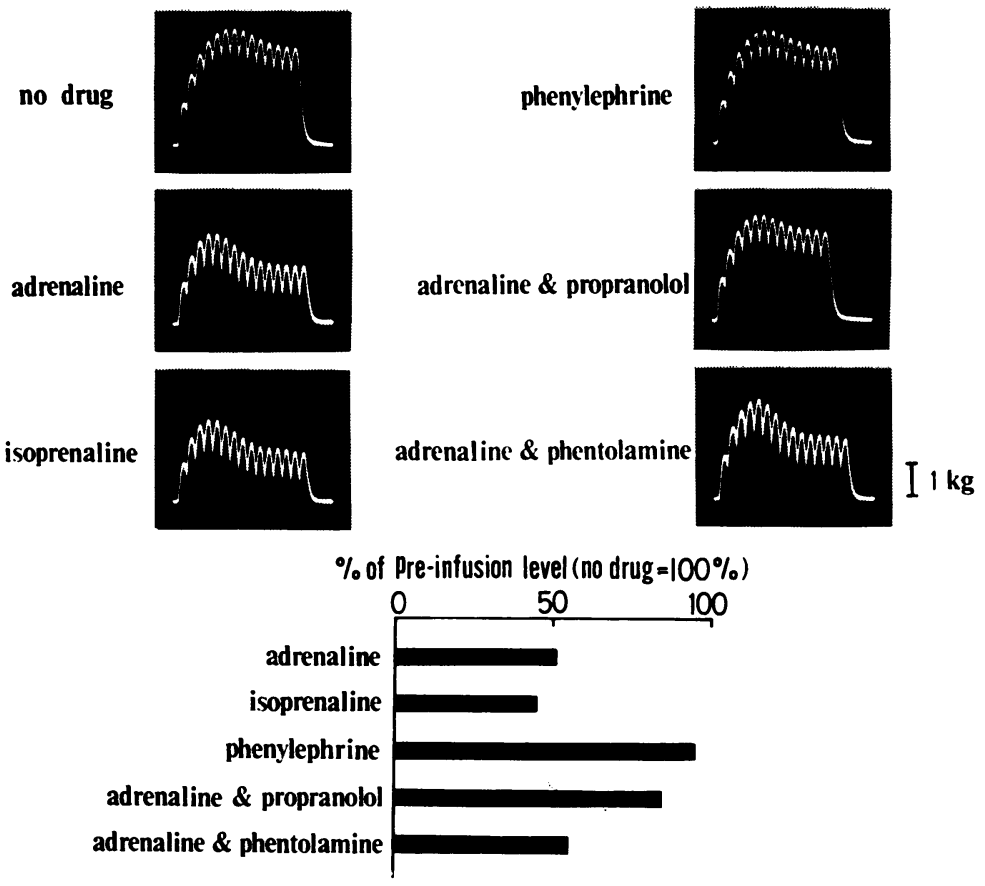

FIG. 8 Effects of sympathomimetic drugs and adrenergic blockers on incomplete tetanus $(10 \mathrm{~Hz})$ in patient demonstrated in Fig. 7. On bottom, effects are shown graphically using the median tension of 10th response (incomplete tetanus); $100 \%$ corresponds to the median tension measured before administrations. 
provided no remarkable additional effect on adrenaline action $(55 \%)$. Isoprenaline (betastimulant) produced the same magnitude of reduction as adrenaline $(45 \%)$ while phenylephrine (alpha-stimulant) had no significant effect on the incomplete tetanus $(95 \%)$ (Fig. 8).

\section{DISCUSSION}

CONTRACTILE PROPERTIES In the present study, the active state was estimated in terms of intensities of shortening and load-bearing, duration, and decay (Table). The active state intensity of shortening is related to the rate of tension development, particularly that attained in the very early phase of contraction, and is looked upon as a measure of the amount of calcium released from the sarcoplasmic reticulum in the initiation of excitation-contraction coupling; this is reflected by the very early phase of the first differential curve of the isometric twitch (Sandow et al., 1965; Sandow, 1965; Desmedt and Hainaut, 1968; Taylor et al., 1969). We, therefore, estimated this factor of active state by measuring the maximum acceleration of twitch development $\left(\mathrm{d}^{2}{ }_{\mathrm{Pt} / \mathrm{dt}}\right)$. The duration of active state was estimated by measuring the time between the onset of the muscle action potential and the peak of the first differential curve $\left(\mathrm{T}_{\mathrm{dPt} / \mathrm{dt}}\right)$; this is based on the concept by Macpherson and Wilkie (1954) who demonstrated that the decay of active state occurs immediately before the first differential curve reaches its peak. This factor depends on the amount of calcium liberated from the sarcoplasmic reticulum and also on the rate at which calcium is utilized by the contractile machinery (Close, 1964). Since the muscle is not stimulated massively, the $\mathrm{T}_{\mathrm{dPt} / \mathrm{dt}}$ may also include the time for the propagation of activity along the membrane system. The decay of active state was expressed by $T_{1 / 2 R}$ in the present study; this factor is reflected by the removal of calcium from troponin and the reaccumulation of calcium by the sarcoplasmic reticulum, and also influences, in part, the time course expressed by $\mathrm{T}_{\mathrm{dPt} / \mathrm{dt}}$ (Taylor et al., 1969; Sandow, 1970; Close, 1972). The active state intensity of load-bearing was measured by the maximum tetanic force $\left(\mathrm{P}_{\mathrm{o}}\right)$ and is attributed to the number and intrinsic strength of the actin-myosin cross-bridges when the sliding-filament mechanism is fully activated

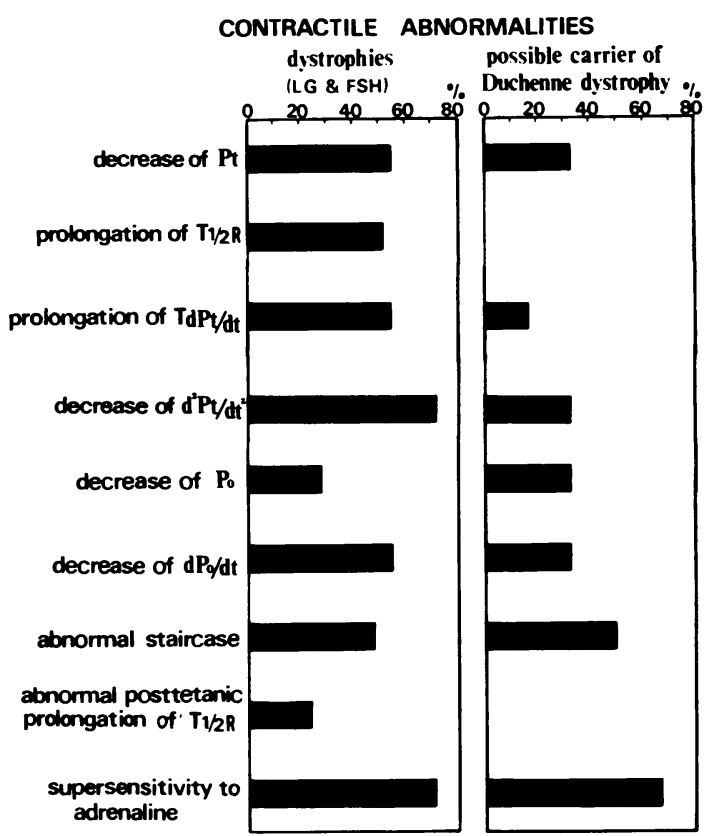

FIG. 9 Incidence of contractile abnormalities in 23 limb-girdle (LG) and six facioscapulohumeral (FSH) dystrophies, and six possible carriers of Duchenne dystrophy at the time when there was no alteration of needle electromyography and evoked muscle action potentials.

(Sandow, 1965). The maximum velocity of tetanus development $\left(\mathrm{d}_{\mathrm{Po} / \mathrm{dt}}\right)$ is reflected by the force-velocity relation of the contractile material if not contaminated by abnormal series-elastic component (Buller and Lewis, 1965).

The post-tetanic twitch potentiation was associated with an increase of the active state intensity of shortening $\left(\mathrm{d}^{2}{ }_{\mathrm{Pt} / \mathrm{dt}}{ }^{2}\right)$ and a protracted decay of the active state $\left(\mathrm{T}_{1 / 2 \mathrm{R}}\right)$ (Fig. 4) (Close and Hoh, 1968; Takamori et al., 1971). Potentiation of the staircase twitch was associated with an increase of the active state intensity of shortening $\left(\mathrm{d}^{2}{ }_{\mathrm{Pt} / \mathrm{dt}^{2}}\right)$ and a shortening of the duration $\left(T_{\mathrm{dPt} / \mathrm{dt}}\right)$ and decay $\left(\mathrm{T}_{1 / 2 \mathrm{R}}\right)$ of the active state (Fig. 5) (Desmedt and Hainaut, 1968; Takamori et al., 1971).

In the adductor pollicis muscle, at the time when there was no alteration in evoked muscle action potentials and needle electromyography, a variety of contractile abnormalities were found in limb-girdle and facioscapulohumeral dys- 
trophic patients and also in possible carriers of Duchenne dystrophy (Figs 2-5, and Fig. 9). Abnormalities in 29 dystrophic patients were noted particularly in the maximum acceleration of twitch development (active state intensity of shortening, $\left.\mathrm{d}^{2}{ }_{\mathrm{Pt} / \mathrm{dt}^{2}}\right)(72 \%$ of patients studied), the maximum velocity of tetanus development (force-velocity relation, $\left.\mathrm{d}_{\mathrm{Po} / \mathrm{dt}}\right)(55 \%)$, the time needed to reach maximum velocity after stimulation (duration of active state, $\left.\mathrm{T}_{\mathrm{dPt} / \mathrm{dt}}\right)(55 \%)$, relaxation time (decay of active state, $T_{1 / 2 R}$ ) $(52 \%)$, and the staircase phenomenon $(48 \%)$. A remarkable abnormality in six possible carriers of Duchenne dystrophy was noted in the study of staircase phenomenon $(50 \%)$. None of the Duchenne dystrophy carriers showed prolongation of the relaxation time in unconditioned and tetanus-conditioned twitches; in this group, the tension output was more involved than the time component of the active state in percentage (Fig. 9). Otherwise, no qualitative difference was noted between the three dystrophic groups.

In view of the current concepts of muscle contraction (Sandow, 1970; Close, 1972), these abnormalities may reflect defects in the subcellular calcium transport system controlled by the sarcoplasmic reticulum (Ebashi and Endo, 1968). They occurred in muscles with normal needle electromyographic activity and normal parameters of evoked muscle action potentials; this fact is similar to that noted in some of the patients with Duchenne dystrophy reported by Desmedt et al. (1968). McComas et al. (1974) reported that a minimum reduction of motor unit population could be present in the dystrophic thenar muscle which shows normal parameters of the maximum evoked muscle action potential. Taking their postulate into account, one may not exclude the possibility that the present study dealt with muscle contraction provided by the surviving motor units.

ADRENALINE EFFECTS ON MUSCLE CONTRACTION In cats and rabbits, adrenaline increases the tension and duration of twitch in fast-contracting muscles, but decreases twitch tension and duration in slow-contracting muscles (Bowman et al., 1962). In man, adrenaline decreases the incomplete tetanus in calf muscle and adductor pollicis, although single twitch changes by adrenaline were not consistent and there was no adrenaline effect on maximum tetanus (Marsden and Meadows, 1970). The extent of adrenaline effect appears to depend on the proportion of slow fibres in the muscle (Bowman and Nott, 1969). These contractile changes induced by adrenaline were independent of vascular changes; receptors to adrenaline must exist in muscles themselves (Bowman et al., 1962; Bowman and Nott, 1969; Marsden and Meadows, 1970). In the present investigation, the incomplete tetanus of the adductor pollicis decreased after adrenaline in 10 normal subjects, and this adrenalineinduced decrease was greater than the normal range in 15 of 21 dystrophic patients $(71 \%)$ and in four of six possible carriers of Duchenne dystrophy (67\%) (Figs 6 and 9). Supersensitivity to adrenaline was more pronounced than abnormalities in other contractile properties in percentage (Fig. 9), and these tests may be useful in the detection of carriers of Duchenne dystrophy.

Abnormal chemosensitive reaction to adrenaline was also reported by Hinterbuchner et al. (1966) in dystrophic mouse muscle, but the inferred it as a reaction due to alteration in neuromuscular transmission. The present resulti however, was obtained without change in muscle $\overrightarrow{0}$ action potentials evoked by the nerve (Fig. 7) 갈 The effect of adrenaline was also confirmed to be independent of vascular changes assessed by monitoring the blood pressure, heart rate and muscle temperature during the infusion of adrenaline in normal or dystrophic human subjects.

The influence of adrenaline on muscle contraction was mediated principally through the betareceptor, since it was abolished by beta-blockers but not by alpha-blockers, and was mimicked by beta-stimulant but not by alpha-stimulant drugs (Fig. 8). This action appears to be different from that underlying the presynaptic action of adrenaline in neuromuscular transmission, for which the alpha-receptor is responsible (Bowman 0 and Raper, 1966; Takamori et al., 1973).

Two effects of adrenaline on muscle tissue, increased glycogenolysis and changes in contraction-relaxation cycle, have been postulated (Bowman and Nott, 1969; Marsden and 0 Meadows, 1970; Rasmussen et al., 1972; $\mathrm{W}$ Sullivan and Zaimis, 1973; Tashiro, 1973). In? the latter, adrenaline activates the adenyl $\stackrel{0}{ᄃ}$ 
cyclase-cyclic AMP system to potentiate either the release of sarcoplasmic calcium, thereby leading to prolongation of the active state in fast-contracting muscle, or the accumulation of calcium by the sarcoplasmic reticulum, thus leading to curtailment of the active state in slowcontracting muscle. Independent of the adenyl cyclase-cyclic AMP system, membrane hyperpolarization induced by adrenaline could also enhance release of sarcoplasmic calcium. The abnormal contractile response to adrenaline in dystrophic muscle, manifested by decrease of the incomplete tetanus and increase of the peak-totrough oscillation (Figs 6 and 7), may reflect disturbance(s) in adrenaline-effective processes such as the above-mentioned subcellular calcium transport system or carbohydrate metabolism of the muscle (Bowman and Raper, 1964).

It has been observed that denervation has an influence on the calcium transport system controlled by the sarcoplasmic reticulum in muscle (Howell et al., 1966; Mommaerts et al., 1969; Sreter, 1970; Margreth et al., 1973), and also produces an abnormal reaction of muscle contraction to adrenaline (Bowman and Raper, 1965; Evans and Smith, 1973). In view of these reports, the results obtained from the present study support the idea that in muscular dystrophy, the nerve axon fails to provide a supply of some moderating element which the muscle requires in order to maintain its normal state of receptivity to pharmacological agents (Baker et al., 1960).

This investigation was supported in part by the research grant funded by the Japanese Ministry of Health and Welfare.

\section{REFERENCES}

Baker, N., Wilson, L., Oldendorf, W., and Blahd, W. H. (1960). Supersensitivity to neostigmine and resistance to d-tubocurarine in mice with hereditary myopathy. American Journal of Physiology, 198, 926-930.

Bowman, W. C., Goldberg, A. A. J., Raper, C. (1962). A comparison between the effects of a tetanus and the effects of sympathomimetic amines on fast- and slow-contracting mammalian muscles. British Journal of Pharmacology and Chemotherapy, 19, 464-484.

Bowman, W. C., and Nott, M. W. (1969). Actions of sympathomimetic amines and their antagonists on skeletal muscle. Pharmacological Reviews, 21, 27-72.

Bowman, W. C., and Raper, C. (1964). The effects of adrenaline and other drugs affecting carbohydrate metabolism on contractions of the rat diaphragm. British Journal of Pharmacology and Chemotherapy, 23, 184-200.
Bowman, W. C., and Raper, C. (1965). The effects of sympathomimetic amines on chronically denervated skeletal muscle. British Journal of Pharmacology and Chemotherapy, 24, 98-109.

Bowman, W. C., and Raper, C. (1966). Effects of sympathomimetic amines on neuromusclar transmission. British Journal of Pharmacology and Chemotherapy, 27, 313-331.

Brown, M. C., and Matthews, P. B. C. (1960). The effect on a muscle twitch of the back-response of its motor nerve fibres. Journal of Physiology, 150, 332-346.

Buller, A. J. (1969). The physiology of the motor unit. In Disorders of Voluntary Muscle, 2nd edn, pp. 17-27. Edited by J. N. Walton. Churchill: London.

Buller, A. J., and Lewis, D. M. (1965). Further observations on the differentiation of skeletal muscles in the kitten hind limb. Journal of Physiology, 176, 355-370.

Close, R. I. (1964). Dynamic properties of fast and slow skeletal muscles of the rat during development. Journal of Physiology, 173, 74-95.

Close, R. I. (1972). Dynamic properties of mammalian skeletal muscles. Physiological Reviews, 52, 129-197.

Close, R. I., and Hoh, J. F. Y. (1968). The after-effects of repetitive stimulation on the isometric twitch contraction of rat fast skeletal muscle. Journal of Physiology, 197, 461477.

Desmedt, J. E., Emeryk, B., Renoirte, P., and Hainaut, K. (1968). Disorder of muscle contraction processes in sexlinked (Duchenne) muscular dystrophy, with correlative electromyographic study of myopathic involvement in small hand muscles. American Journal of Medicine, 45, 853-872.

Desmedt, J. E., and Hainaut, K. (1968). Kinetics of myofilament activation in potentiated contraction: staircase phenomenon in human skeletal muscle. Nature, 217, 529532.

Ebashi, S., and Endo, M. (1968). Calcium ion and muscle contraction. In Progress in Biophysics and Molecular Biology, vol. 18, pp. 123-183. Edited by J. A. V. Butler and D. Noble. Pergamon Press: Oxford.

Evans, R. H., and Smith, J. W. (1973). Mode of action of catecholamines on skeletal muscle. Journal of Physiology, 232, 81P-83P.

Hinterbuchner, L. P., Angyan, A., and Hirsch, M. (1966). Effect of series of tetani on dystrophic and normal muscles of mouse. American Journal of Physiology, 211, 915-918.

Howell, J. N., Fairhurst, A. S., Jenden, D. J. (1966). Alterations of the calcium accumulating ability of striated muscle following denervation. Life Sciences, 5, 439-446.

McComas, A. J., Sica, R. E. P., and Upton, A. R. M. (1974). Multiple muscle analysis of motor units in muscular dystrophy. Archives of Neurology, 30, 249-251.

Macpherson, L., and Wilkie, D. R. (1954). The duration of the active state in a muscle twitch. Journal of Physiology, 124, 292-299.

Margreth, A., Salviati, G., and Carraro, U. (1973). Neural control on the activity of the calcium-transport system in sarcoplasmic reticulum of rat skeletal muscle. Nature, 241, 285-286.

Marsden, C. D., and Meadows, J. C. (1970). The effect of adrenaline on the contraction of human muscle. Journal of Physiology, 207, 429-448.

Merton, P. A. (1954). Interaction between muscle fibres in a twitch. Journal of Physiology, 124, 311-324.

Mommaerts, W. F. H. M., Buller, A. J., and Seraydarian, K. (1969). The modification of some biochemical properties of muscle by cross-innervation. Proceedings of the National Academy of Sciences of the United States of America, 64, 128-133. 
Rasmussen, H., Goodman, D. B. P., and Tenenhouse, A. (1972). The role of cyclic AMP and calcium in cell activation. CRC Critical Reviews in Biochemistry, 1, 95-148.

Sandow, A. (1965). Excitation-contraction coupling in skeletal muscle. Pharmacological Reviews, 17, 265-320.

Sandow, A. (1970). Skeletal muscle. Annual Review of Physiology, 32, 87-138.

Sandow, A., Taylor, S. R., and Preiser, H. (1965). Role of the action potential in excitation-contraction coupling. Federation Proceedings, 24, 1116-1123.

Slomić, A., Rosenfalck, A., and Buchthal, F. (1968). Electrical and mechanical responses of normal and myasthenic muscle, with particular reference to the staircase phenomenon. Brain Research, 10, 1-78.

Sreter, F. A. (1970). Effect of denervation on fragmented sarcoplasmic reticulum of white and red muscle. Experimental Neurology, 29, 52-64.

Sullivan, A., and Zaimis, E. (1973). The effect of isoprenaline on cyclic AMP concentrations in skeletal muscle. Journal of Physiology, 231, 102P-103P.
Takamori, M. (1972). Caffeine, calcium, and EatonLambert syndrome. Archives of Neurology, 27, 285-291.

Takamori, M., Gutmann, L., Crosby, T. W., and Martin, J. D. (1972). Myasthenic syndromes in hypothyroidism. Electrophysiological study of neuromuscular transmission and muscle contraction in two patients. Archives of Neurology, 26, 326-335.

Takamori, M., Gutmann, L., and Shane, S. R. (1971). Contractile properties of human skeletal muscle: Normal and thyroid disease. Archives of Neurology, 25, 535-546.

Takamori, M., Ishii, N., and Mori, M. (1973). The role of cyclic $3^{\prime}, 5^{\prime}$-adenosine monophosphate in neuromuscular transmission. Archives of Neurology, 29, 420-424.

Tashiro, N. (1973). Effects of isoprenaline on contractions of directly stimulated fast and slow skeletal muscles of the guinea-pig. British Journal of Pharmacology, 48, 121-131.

Taylor, S. R., Preiser, H., and Sandow, A. (1969). Mechanical threshold as a factor in excitation-contraction coupling. on Journal of General Physiology, 54, 352-368. 